\title{
Phagocytosis of Simulated Nano-wear Debris by Osteoblasts
}

\author{
Mrinal K Musib ${ }^{1,2}$ \\ ${ }^{1}$ Department of Orthopaedic Surgery and Rehabilitation Medicine, SUNY Downstate Medical Center, Brooklyn, NY 11203, USA \\ ${ }^{2}$ Department of Orthopaedic Surgery, University of Texas Health Science Center, San Antonio, TX 78229
}

\begin{abstract}
In this study I have used well characterized simulated wear-nano-particles of ultra-high molecular weight polyethylene (UHMWPE) of known size and shape to study particulate phagocytosis by MG63 osteoblast-like cells. The particles were treated to decrease their propensity to form aggregates in aqueous suspension and scanning electron microscopy (SEM) was performed to image them as individual particles on $0.01 \mu \mathrm{m}$ pore size polycarbonate filter membranes. These images were further subjected to morphometric analysis of the particles using ASTM F1877 descriptors [equivalent circle diameter (ECD in $\mu \mathrm{m}$ ), aspect ratio (AR), elongation (E), roundness (R), and formfactor (FF)]. The mean $( \pm \mathrm{SD}) \mathrm{ECD}$ of the particles were $0.056 \pm 0.03 \mu \mathrm{m}$. They were subsequently introduced to confluent MG63 cells at particle:cell ratio of 100:1 and incubated for $24 \mathrm{~h}$. Transmission electron micrography (TEM) showed the nanoparticles inside the cytosol. No time dependent response was observed beyond $24 \mathrm{~h}$. The nanoparticles seemed to re-agglomerate once inside the cell. The damage to the cells was evident from the compromised cell membrane. This study will help further our knowledge of the wear-mediated osteolytic process.
\end{abstract}

Keywords Nanoparticles, Phagocytosis, Osteoblasts, SEM, TEM, Orthopedic Wear Debris

\section{Introduction}

Wear debris, primarily of UHMWPE are continually released at the articulating surfaces of most orthopedic total joints. Cellular response to the debris is the primary cause that limits the longevity of such implants ${ }^{1-9}$. Various cell lineages phagocytose/endocytose such non-biodegradable particulates resulting in the release of chemical entities, which has been hypothesized as one of the fundamental events that occur when wear-debris come in contact with surrounding cells ${ }^{10-15}$. But evidence showing UHMWPE particle phagocytosis, particularly the nanoparticles $<100$ $\mathrm{nm}$ by MG63 osteoblast-like cells (which is widely used as a model to study in vitro cellular response) is lacking. This may be attributed among other things to difficulties associated in handling UHMWPE nanoparticles. Furthermore size and shape are important attributes that dictate rate and extent of phagocytosis ${ }^{16-20}$. Figure 1 (a-c) shows the various steps/scenarios involved in phagocytosis. The cells initially identify the target and the particles adhere to the cell surface, followed by its internalization (a). Theprocess continues till the cell gets saturated with particles and can no longer phagocytose more particles (b), which

* Corresponding author:

musib.mrinal@gmail.com (Mrinal Musib)

Published online at http://journal.sapub.org/nn

Copyright (C) 2011 Scientific \& Academic Publishing. All Rights Reserved may be referred to as the "phagocytotic capacity" of that particular cell type. It can be calculated using images/dimensions of the particles including its length, width and thickness. There may also be large non phagocytosable particles (c) and some studies hypothesize the limiting size of such wear particles to be about $10 \mu \mathrm{m}$ for most cell types although there is no clear consensus in this regard.

Cells tend to attach to the particle surface and wrap around the particle ${ }^{10}$ prior to internalizing the particle. Engulfment of a particle involves the following critical steps: cell-particle interaction and subsequent adhesion, cell activation and projection of membrane-bound cytoplasm around the particle, and membrane fusion to include the particle ${ }^{21,22}$. The number of phagocytosed particles depends on several factors: cell type and morphometry, cell growth environment, chemical composition of the particle, surface property of the particle, and size and shape of the particle. The phagocytotic capacity (\% volume of cell occupied by particles) will depend on the various size-shape descriptors as mentioned before like ECD, AR and $\mathrm{R}^{12,23,24}$.

Previous investigators have studied the role of size in phagocytosis, both biological and theoretical ${ }^{25}$. Simon et al, studied the phagocytosis of polystyrene microspheres $(0.5-8.0 \mu \mathrm{m})$ by human blood neutrophils and found that phagocytosis decreased with increasing particle size ${ }^{20}$. Neale et al, investigated phagocytosis of polymeric and metallic biomaterials $(0.5-3.0 \mu \mathrm{m})$ and found that all particles were 
phagocytosed resulting in inhibition of cellular functions ${ }^{11}$. Okafor et al, used cpTi particles $(0.519 \pm 0.125 \mu \mathrm{m})$ to study endocytosis by human mesenchymal stem cells and found the particles to be cytotoxic once they are internalized ${ }^{12}$. They identified using SEM and confocal microscopy that the particles are localized in the cytoplasm. Wang et al, used latex particles $(0.1-10.0 \mu \mathrm{m})$ and identified them in human and rat osteocasts in as little as $2 \mathrm{~h}^{13}$. Thus it seems that attachment followed by internalization of particles is an innate property of most cell types that dictate their subsequent response and biological behavior.
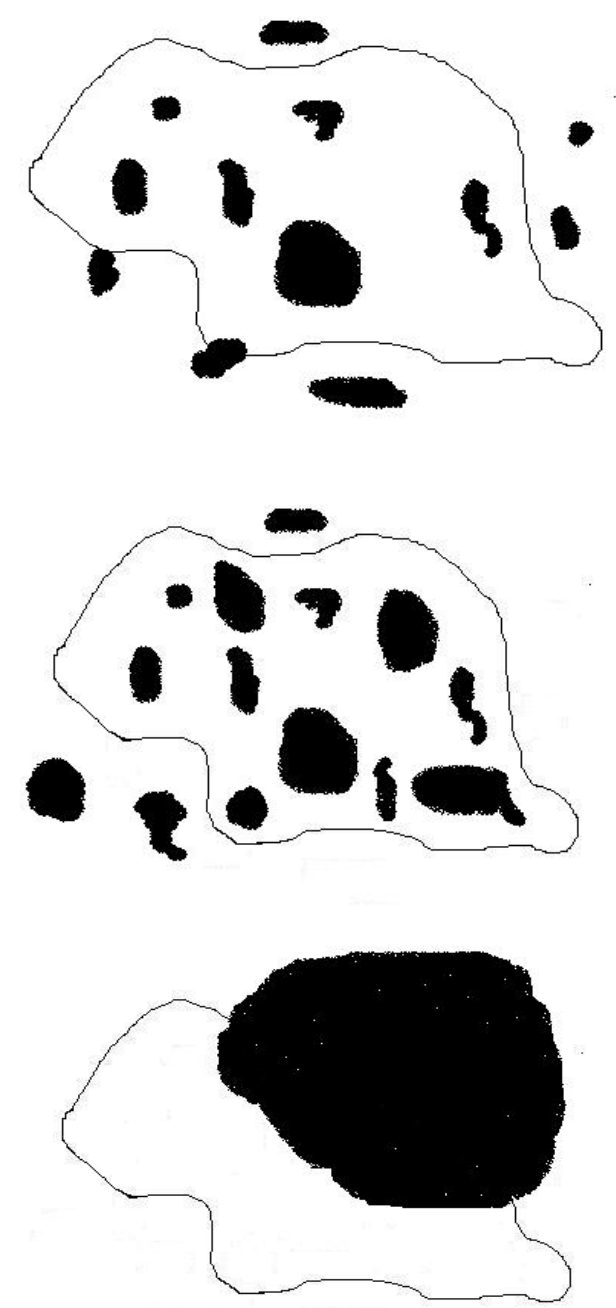

Figure 1. Three different scenario during phagocytosis; a) Sub-confluent phagocytosis: Cell-particles encounter, followed by particle attaching to cell membrane and subsequently being internalized, cell not saturated with particles (top), b) Confluent phagocytosis: excess phagocytosable particles, cell overwhelmed with particles and cannot phagocytose more (middle); and c) Large non-phagocytosable particles

Although previous investigators have studied cellular endocytosis of biologically relevant particles, most of them suffer from numerous shortcomings including using only spherical targets or larger particles that have not been well characterized $^{13,20,26,27}$. In my opinion this is the first study to investigate phagocytosis of clinically relevant and well characterized simulated wear nano-particles $(<100 \mathrm{~nm})$ using a widely used cell line (MG63 osteoblast-like cells). Further research will be conducted to study in vivo response to these particles.

\section{Materials and Methods}

\subsection{Preparation of Particle Suspensions}

The method used to fractionate and characterize the particles has been explained elsewhere ${ }^{28}$. In short, $1 \mathrm{mg} / 1 \mathrm{ml}$ of GUR 1050 resin (Ticona) was suspended in acidified water (pH 5.5) containing 2000 ppm of surfactant Pluronic F127 (Sigma-Aldrich, catalog \#P2443-250G). Suspensions were vortexed for 5 minutes, sonicated for 120 minutes and filtered through appropriate pore size filter to remove larger particles.

The nano-fraction particles were collected on $0.01 \mu \mathrm{m}$ pore size polycarbonate filters (Osmonics). All filter membranes were washed with $1 \mathrm{ml}$ of $\mathrm{dd} \mathrm{H}_{2} \mathrm{O}$ to dissolve any salt crystals that may be present and to further disperse the particles throughout the membrane to facilitate viewing of individual particles.

One of the particulate-containing $0.01 \mu \mathrm{m}$ filter was air dried, adhesive-fixed onto a SEM stub and sputter coated with $\mathrm{Au}-\mathrm{Pd}(25 \mathrm{~nm})$. Eight to ten images were obtained at varying magnifications using an SEM. Using the images, a morphometric analysis of 300 particles was performed using the 5 size-shape descriptors as mentioned in the Particle Morphology Analysis (PMA) program described in ASTM standard F1877 $7^{29-31}$.

\subsection{Preparation of $10 \%$ FBS Media Containing Particles for Cell Response Studies}

The number of particles in a unit volume of the original suspension was quantified (from the SEM images) using the 'UTHSCSA Image' program and the results were extrapolated to calculate the number of nano-particles in 1 $\mathrm{mg}$ of the original suspension. Particles present on the unprocessed filter membranes were tested for the presence of endotoxin using an E-TOXATE kit (Sigma-Aldrich, catalog \#ET0100) and were found to be endotoxin negative and subsequently resuspended in DMEM containing 10\% FBS. This stock suspension containing a known number of the nano-particles per unit volume was further sonicated for 5 min and stored at $4^{\circ} \mathrm{C}$ for 7 days before being used in cell response studies.

\subsection{MG63 Osteoblast like Cells}

The MG63 cell line was obtained from the American Type Culture collection (Rockville, MD). It was originally isolated from a human osteosarcoma and showed numerous osteoblastic traits and is transformed. MG63 cells are clonal (one cell type) and do not form a calcifiable matrix. They are considered a model of an immature osteoblast because they respond to $1,25-(\mathrm{OH})_{2}$ vitamin $\mathrm{D}_{3}$ and parathyroid hormone by increasing alkaline phosphatase specific activity. Cells were plated at 9300 cells $/ \mathrm{cm}^{2}$ in Dulbecco's modified eagle 
medium (DMEM) containing 10\% FBS and $0.5 \%$ antibiotics. They were cultured in an atmosphere of $100 \%$ humidity, $5 \%$ $\mathrm{CO}_{2}$ and $37^{\circ} \mathrm{C}$ and allowed to confluence.

\subsection{Particles Used}

Prior to removing an aliquot of the media containing a known number of particles per unit volume of the suspension the tube was vortexed for 5 seconds to resuspend the particles uniformly. Particles at the ratio of 100 per cell were introduced to the culture and the cells were allowed to be in contact with the particles for $24 \mathrm{~h}$ in an incubator. The control had no particles but fresh media. The volume of the particle-containing media used was just enough to cover the surface of the cells and the media was shaken occasionally to facilitate the interaction of cells and particles.

At harvest, experimental media was removed from cultures and cell layers were washed three times with PBS. The cell layers were removed by trypsinisation. The cells were centrifuged $(500 \mathrm{~g}, 10 \mathrm{~min})$ and pellets post-fixed in $1 \%$ $\mathrm{OsO}_{4}$. The samples were embedded in Epon and $90 \mathrm{~nm}$ sections cut with a diamond knife, mounted on copper grids, stained with $1 \%$ uranyl acetate and lead citrate and examined with a TEM (Philips, Leicester, UK) at $60 \mathrm{kV}$.

\section{Results}

\subsection{Particle Characterization}

ASTM F1877 descriptors were used to perform morphometric analysis of the particles. Table 1 shows the results of the size-shape analysis and other statistical parameters for 300 UHMWPE particles.

Table 1. Size-shape analysis of 300 GUR 1050 nano-particles

\begin{tabular}{|c|c|c|c|c|}
\hline $\begin{array}{c}\mathbf{E C D} \pm \mathbf{S D} \\
(\boldsymbol{\mu m})\end{array}$ & $\begin{array}{c}\text { Min } \\
(\boldsymbol{\mu m})\end{array}$ & $\mathbf{A R} \pm \mathbf{S D}$ & $\mathbf{E} \pm \mathbf{S D}$ & $\mathbf{R} \pm \mathbf{S D}$ \\
\hline $0.056 \pm 0.03$ & 0.015 & $1.37 \pm 0.25$ & $1.49 \pm 0.34$ & $0.82 \pm 0.13$ \\
\hline
\end{tabular}

All particles were within their designated size ranges showing the efficacy, accuracy and reproducibility of the filtration method. The ECD of the smallest particle isolated was $15 \mathrm{~nm}$. Figures $2 \mathrm{a}$ and $\mathrm{b}$ are representative SEM images showing well dispersed, individual UHMWPE nanoparticles on the $0.01 \mu \mathrm{m}$ pore filter. The treatment seems to have decreased their tendency to form agglomerates.

\subsection{Phagocytosis}

TEM analysis was performed after $24 \mathrm{~h}$ of incubation and confirmed the internalization of the UHMWPE particles, most cells having internalized several particles. Although most of the particles were in the cytosol, some particles were attached to the cell membrane. MG63 cells cultured without particles had a round or oblong nucleus with one or two nucleoli (Figure 3). The cell membrane was intact and other organelles including the Golgi apparatus and mitochondria were discernable under the TEM. Following exposure to particles, MG63 cells showed a marked change in their morphology.
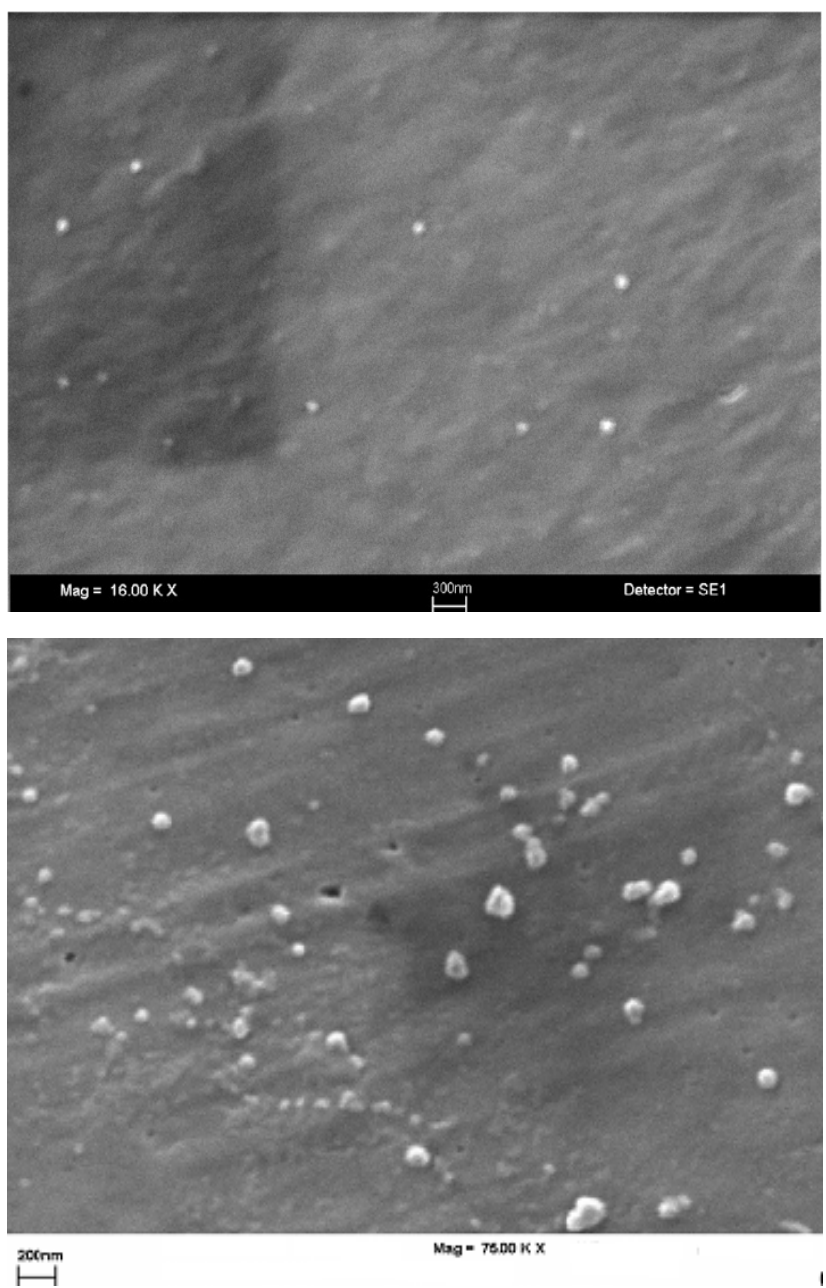

Figure 2. Representative SEM micrographs of the nanofraction particles collected on a $0.01 \mu \mathrm{m}$ pore filter. Magnification is a) $16,000 \mathrm{X}$ (top) and b) $75,000 \mathrm{X}$

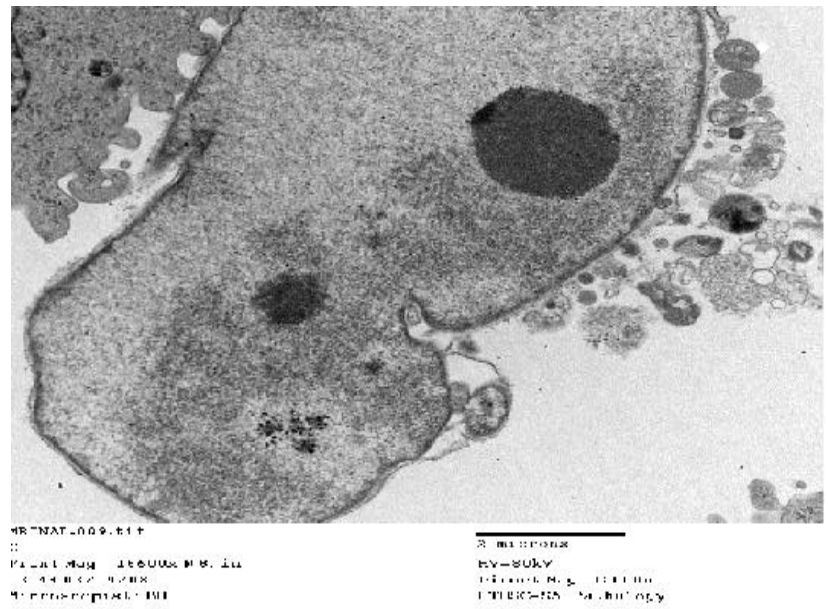

Figure 3. TEM image of representative MG63 cells that have not been treated with particles (control)

The cell membrane was compromised (Fig 4). In addition, there were lysosomal-like elements and large Golgi extensions, reduced rough endoplasmic reticulum, and 
granular inclusions. The cell membrane was ruffled and torn and the cells developed cytoplasmic extensions.

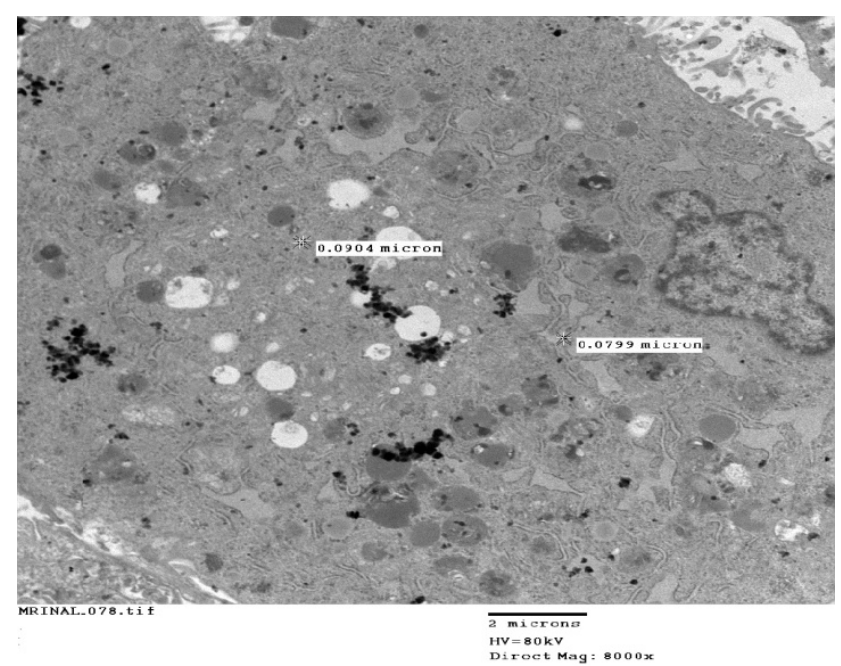

Figure 4. Representative TEM image of MG63 cell that has been treated with the nano- sized UHMWPE particles. The cell membrane of the treated cells are ruffled and numerous nano-particles can be seen inside the cell; many as agglomerates. Magnification is $8,000 \mathrm{x}$

Determining the exact number of phagocytosed particles/cell is difficult because of the indiscernible location of phagocytosed, partially engulfed, or surface-attached particles and the intracellular aggregation of the phagocytosed UHMWPE particles. The amount of particles incorporated into the cells varied from cell to cell, but a maximum of 30 particles phagocytosed within $24 \mathrm{~h}$ for the cells treated with nanoparticles seems to be the saturation level for MG63 cells. This may relate to the phagocytotic capacity of each cell and that the ratio of particle volume/cell volume is an important factor that determines the phagocytotic ability of the cells.

Furthermore, in vitro studies were conducted to investigate the effects of size and dose (using nano and submicron particles $(0.2-1.0 \mu \mathrm{m})$ of polymeric and metallic particles and the nanoparticles were found to be more deleterious to osteoblasts, data not shown).

\section{Discussion}

With the introduction of improved wear resistant materials (like highly cross-linked UHMWPE) to fabricate total joint components, there has been a decrease in wear debris volume, but has led to increased generation of nano-debris ${ }^{32}$. Although a well corroborated mechanism as to how cells respond to nano-wear-debris is presently elusive, even these smaller nano-size particles (like their larger counterparts) are phagocytosed by cells prior to eliciting a biological response. As evident from the results of this study, cells phagocytosed the nanoparticles resulting in damaged cell membrane. Further research needs to be initiated to investigate the exact mechanism (selective phagocytosis or endocytosis) involved in the process of particular intake and also the fate of even smaller particles $(<50 \mathrm{~nm})$.
According to my knowledge, this is the first study showing the presence of nanoparticles $(<100 \mathrm{~nm})$ of UHMWPE inside MG63 cells. Previous investigators have also identified larger particles inside a plethora of cell types. Phagocytosis seems to be an inherent property of most cell types and this phenomenon involving non-biodegradable wear-debris results in the release of various chemical entities including inflammatory mediators, cytokines and chemokines by cells eventually leading to implant failure. In this investigation we have identified smaller particles, some as small as few tens of nanometers, inside the cytoplasm of osteoblasts. The resulting damage to the cell membrane is evident, and accompanied by the cell's frustration in not being able to degrade/digest/expel these particles may be responsible for eventual cellular toxicity and death. Furthermore it is an interesting observation that the smaller particles tend to form agglomerates when inside the cytosol, the exact repurcations of which is not very clear. Previous investigators have hypothesized that smaller submicron sized particles may be internalized by cells by the phenomenon of pinocytosis, thus minimizing cellular damage, if any. This is in contradiction to the observations/results of this study, wherein we see extensive damage to cell membrane due to phagocytosis of the nanoparticles.

There are very few specific studies involving usage of TEM and well characterized particles of UHMWPE to study cellular phagocytosis. Among other reasons it may be attributed to difficulties associated in handling these particles. As compared to other electron microscopic techniques, TEM may be better suited for such studies as the electron dense particles may be easily identified/distinguished as dark structures amongst the cellular organelles.

The present work enhances our understanding of the size-shape dependent phagocytosis of nano-particles. Cells seem to identify their targets based on their size and topography/morphology. Eventually only a certain volume fraction of the cell may be occupied (phagocytotic limit) which we hypothesize would be distinct for individual cell types, beyond which cells will lose the affinity and ability to internalize more particles. Moreover cells seem to favor internalization of spherical particles (particles with higher ' $R$ ' and lower 'AR' and ' $E$ ' values), which has also been shown by other researchers ${ }^{10}$. This innate property of cells may have immense bearing in the field of drug delivery. Another striking observation was the presence of membrane ruffles, which are dynamic actin filaments and are assumed to be associated with actin-dependent internalization process during phagocytosis. Further investigations are needed to properly understand the creation and involvement of these filaments/ruffles in response to varying size and shape of the target particles.

This study may also point to the importance and relevance of one of the most fundamental features of target molecules/particles, their size and shape, in the size-shape-dependent phagocytotic process. Non-usage of clinically relevant, well characterized, non-spherical 
particles as may be present in situ in an actual in vivo situation, which has been a shortcoming of previous studies, has been addressed in this investigation. Preliminary investigations also show a size dependent response with significantly $(\mathrm{p}<0.01)$ greater number of nanoparticles being phagocytosed as compared to larger particles.

Limitations of this work includes usage of simulated wear particles (although clinically relevant) and not actual wear-debris. The volume of the media containing the particles should be just sufficient to cover the surface of the container and be occasionally shaken to facilitate proper cell-particle interaction. Future work will include isolation, identification, fractionation and characterization of wear-debris from patients and performing in vitro and in vivo studies. Further research needs to be undertaken to study cellular response to even smaller particles, $<50 \mathrm{~nm}$.

\section{REFERENCES}

[1] Campbell P, Kossovsky N, Schmalzried TP. Particles in loose hips. J Bone and Joint Surg.Br 1993; 75(1):161-162.

[2] Schmalzried TP, Campbell P, Schmitt AK, Brown IC, Amstutz HC. Shapes and dimensional characteristics of polyethylene wear particles generated in vivo by total knee replacements compared to total hip replacements. J Biomed Mater Res 1997;38(3):203-210.

[3] Shanbhag AS, Bailey HO, Hwang DS, Cha CW, Eror NG, Rubash HE. Quantitative analysis of ultrahigh molecular weight polyethylene (UHMWPE) wear debris associated with total knee replacements. J Biomed Mater Res 2000;53(1):100-110.

[4] acobs JJ, Shanbhag A, Glant TT, Black J, Galante JO. Wear Debris in Total Joint Replacements. J Am Acad Orthop Surg 1994;2(4):212-220.

[5] Hallab NJ, Jacobs JJ. Biologic effects of implant debris. Bull NYU Hosp Jt Dis 2009;67(2):182-8.

[6] Purdue PE, Koulouvaris P, Nestor BJ, Sculco TP. The central role of wear debris in periprosthetic osteolysis. HSS J : Musculoskeletal J Hosp for Special Surg 2006;2(2):102-113.

[7] Wooley PH, Nasser S, Fitzgerald RH, Jr. The immune response to implant materials in humans. Clin Orthop and Rel Res 1996;(326)(326):63-70.

[8] Wang JY, Wicklund BH, Gustilo RB, Tsukayama DT. Titanium, chromium and cobalt ions modulate the release of bone-associated cytokines by human monocytes/macrophages in vitro. Biomaterials 1996; 17(23):2233-2240.

[9] Goodman SB. Wear particles, periprosthetic osteolysis and the immune system. Biomaterials 2007; 28(34):5044-5048.

[10] Champion JA, Mitragotri S. Shape induced inhibition of phagocytosis of polymer particles. Pharm Res 2009;26(1):244-9.

[11] Neale SD, Haynes DR, Howie DW, Murray DW, Athanasou NA. The effect of particle phagocytosis and metallic wear particles on osteoclast formation and bone resorption in vitro.
J Arthrop 2000;15(5):654-662.

[12] Okafor CC, Haleem-Smith H, Laqueriere P, Manner PA, Tuan RS. Particulate endocytosis mediates biological responses of human mesenchymal stem cells to titanium wear debris. J Orthop Res 2006;24(3):461-473.

[13] Wang W, Ferguson DJ, Quinn JM, Simpson AH, Athanasou NA. Biomaterial particle phagocytosis by bone-resorbing osteoclasts. J Bone and Joint Surg.Br 1997;79(5):849-856.

[14] Pioletti DP, Takei H, Kwon SY, Wood D, Sung KL. The cytotoxic effect of titanium particles phagocytosed by osteoblasts. J Biomed Mater Res 1999;46(3):399-407.

[15] Purdue PE. Alternative macrophage activation in periprosthetic osteolysis. Autoimmunity 2008; 41(3): 212-7.

[16] Champion JA, Mitragotri S. Role of target geometry in phagocytosis. Proc Natl Acad Sci U S A 2006;103(13):4930-4.

[17] Champion JA, Walker A, Mitragotri S. Role of particle size in phagocytosis of polymeric microspheres. Pharm Res 2008;25(8):1815-21.

[18] Lundqvist M, Stigler J, Elia G, Lynch I, Cedervall T, Dawson KA. Nanoparticle size and surface properties determine the protein corona with possible implications for biological impacts. Proc Natl Acad Sc 2008;105(38):14265-70.

[19] O'Connor DT, Choi MG, Kwon SY, Paul Sung KL. New insight into the mechanism of hip prosthesis loosening: effect of titanium debris size on osteoblast function. J Orthop Res 2004;22(2):229-36.

[20] Simon SI, Schmid-Schonbein GW. Biophysical aspects of microsphere engulfment by human neutrophils. Biophys $\mathrm{J}$ 1988;53(2):163-73.

[21] Aderem A, Underhill DM. Mechanisms of phagocytosis in macrophages. Annual Review of Immunology 1999; 17:593-623.

[22] Besterman JM, Airhart JA, Low RB. Macrophage phagocytosis: analysis of particle binding and internalization. Am JPhysio 1982;242(5):C339-46.

[23] Minoda Y, Kobayashi A, Iwaki H, Miyaguchi M, Kadoya Y, Ohashi H, Yamano Y, Takaoka K. Polyethylene wear particles in synovial fluid after total knee arthroplasty. Clin Orthop and Rel Res 2003;(410)(410):165-172.

[24] Ren W, Wu B, Mayton L, Wooley PH. Polyethylene and methyl methacrylate particle-stimulated inflammatory tissue and macrophages up-regulate bone resorption in a murine neonatal calvaria in vitro organ system. J Orthop Res 2002;20(5):1031-1037.

[25] Chen H, Langer R, Edwards DA. A Film Tension Theory of Phagocytosis. J Colloid Interface Sci 1997; 190(1):118-33.

[26] Koval M, Preiter K, Adles C, Stahl PD, Steinberg TH. Size of IgG-opsonized particles determines macrophage response during internalization. Exp Cell Res 1998;242(1):265-73.

[27] Cannon GJ, Swanson JA. The macrophage capacity for phagocytosis. J Cell Sci 1992;101 ( Pt 4):907-13.

[28] Saha S, Musib M. Fractionation and Characterization of Particles Simulating Wear of Total Joint Replacement (TJR) Following ASTM Standards. J Long Term Eff Med Implants 2011;21(1):79-92. 
[29] Mabrey JD, Afsar-Keshmiri A, Engh GA, Sychterz CJ, Wirth MA, Rockwood CA, Agrawal CM. Standardized analysis of UHMWPE wear particles from failed total joint arthroplasties. J Biomed Mater Res 2002;63(5):475-483.

[30] Landry ME, Blanchard CR, Mabrey JD, Wang X, Agrawal CM. Morphology of in vitro generated ultrahigh molecular weight polyethylene wear particles as a function of contact conditions and material parameters. J Biomed Mater Res 1999;48(1):61-69.
[31] Wirth MA, Agrawal CM, Mabrey JD, Dean DD, Blanchard CR, Miller MA, Rockwood CA, Jr. Isolation and characterization of polyethylene wear debris associated with osteolysis following total shoulder arthroplasty. J Bone and Joint Surg.Am 1999; 81(1):29-37.

[32] Tipper JL, Galvin AL, Williams S, McEwen HM, Stone MH, Ingham E, Fisher J. Isolation and characterization of UHMWPE wear particles down to ten nanometers in size from in vitro hip and knee joint simulators. J Biomed Materials Res. A 2006;78(3):473-480. 